\title{
Critical Analysis of the Use of Platelet-rich Plasma in Orthopedic Clinical Practice: An Evolving Story
}

\author{
${ }^{1}$ Saurabh Singh, ${ }^{2}$ Vijay Shetty
}

\begin{abstract}
Orthobiologics are substances that are believed to help injuries heal more quickly. Orthobiologic agents include products, such as stem cells and platelet-rich plasma (PRP) containing various (good and bad) growth factors. The use of PRP in orthopedic clinical practice and evolution of this treatment in sports medicine, over the last decade or so, is a story of innovation, experimentation, controversies, and matter of huge debate.
\end{abstract}

Keywords: Orthopedics, Platelet-rich plasma, Sports medicine.

How to cite this article: Singh S, Shetty V. Critical Analysis of the Use of Platelet-rich Plasma in Orthopedic Clinical Practice: An Evolving Story. J Postgrad Med Edu Res 2018;52(2):53-55.

Source of support: Nil

Conflict of interest: None

\section{THE BEGINNING}

Way back in 2006, researchers in Milan, Italy, published the possible systemic effects of injecting PRP in professional athletes who were suffering from tendinopathies. The conclusion was that the use of PRP may have systemic effects but local effects are clearly longer and beneficial. ${ }^{1}$ This was perhaps one of the earliest reports of the use of PRP in sports-related injuries. Ever since the interest in the use of PRP in orthopedic clinical practice has been growing, given its potential to enhance tendon and muscle healing. ${ }^{2-4}$

\section{THE JOURNEY}

Possibly, the first level II evidence favoring the use of PRP in sports medicine came from Nguyen et al. ${ }^{5}$ The authors concluded that PRP can be a potentially efficacious regenerative treatment option for musculoskeletal and sports medicine applications. An animal experimental study by Spang et $\mathrm{al}^{6}$ in the same year clearly demonstrated that injecting PRP into severed patellar tendons in rats enhances tendon healing. Further, in the same year,

\footnotetext{
${ }^{1}$ Clinical and Research Fellow, ${ }^{2}$ Consultant Orthopedic Surgeon

1,2Department of Orthopedics, Dr L.H. Hiranandani Hospital Mumbai, Maharashtra, India

Corresponding Author: Vijay Shetty, Consultant Orthopedic Surgeon, Department of Orthopedics, Dr L.H. Hiranandani Hospital, Mumbai, Maharashtra, India, Phone: +919920707771 e-mail: vijaydshetty@gmail.com
}

Kon et $\mathrm{al}^{7}$ concluded after a critical analysis of the literature that the literature shows promising preclinical results but contradictory clinical findings for the treatment of sports-related injuries.

While the researchers agreed that PRP is certainly one emerging strategy to accelerate tissue healing, in a variety of clinical conditions, the major question remained; is PRP or any other orthobiologic product for that matter efficient? For a start, there have been wide variations in agreeing on a definition of PRP. ${ }^{8}$ A number of publications started appearing in the literature debating the use of PRP in the early 2010s. ${ }^{9,10}$ Besides, PRP received much media attention for being used by many celebrity athletes for injuries. ${ }^{11,12}$ At this time, what was missing was robust evidence with level I studies to support the use of PRP, including optimal formulation, dosage, and rehabilitation protocols.

The year 2012 saw the first proposed randomized study protocol on the use of PRP for muscle injuries. ${ }^{13}$ The authors targeted "return-to-play" as the main outcome measure. The study was later published in 2014 and concluded that the PRP group did significantly better than the control group. ${ }^{14}$ The overall clinical outcomes after using PRP in clinical practice was still not universally accepted, possibly due to the fact that all PRP preparations were not the same. Many authors reported the variations in the volume of blood taken, the platelet recovery efficacy, the final volume of plasma in which the platelets are suspended, and the presence or absence of leukocytes. ${ }^{15,16}$

\section{INDICATION-SPECIFIC OUTCOMES}

Although some case reports suggested benefits of PRP on the healing of ligaments and tendons, indication-specific outcomes (meniscus, ligaments, rotator cuff, muscle injuries, and articular cartilage pathology) on the use of PRP were not forthcoming until late 2013. ${ }^{17-20}$

Muscle injuries and articular cartilage injuries are a common form of sport-related injuries. ${ }^{21}$ Although the use of PRP in muscle injuries is validated, in terms of early return to play, through a randomized control study by Hamid et $\mathrm{al}^{14}{ }^{14}$ there appears to be paucity of data supporting the use of PRP for the management of focal osteochondral defects as suggested by a systematic review by Dold et al..$^{22}$ The indications for the use of PRP in sports medicine rather exploded in early 2014 . The first double-blind randomized control trial, on the use of PRP for patellar 
tendinopathy, came from Stanford University, California, in March 2014. ${ }^{23}$ The authors concluded that a therapeutic regimen that included the injection of leukocyte-rich PRP accelerated the healing of patellar tendon in the study group. This is an interesting observation, given that there is no previous randomized control trial on the use of PRP in patellar tendinopathy. Going one step further on the use of PRP in sports medicine, researchers in New York studied the use of PRP on tendon-bone-tendon healing, further exploring the opportunities with PRP. ${ }^{24}$ However, this study only mentioned about the possibility of PRP augmenting tendon-bone-tendon healing.

\section{CONTROVERSIES}

The use of PRP, in sport-related injuries, is surrounded by controversies and debates. We now have reasonable evidence that PRP works on tennis elbow. ${ }^{25-27}$ Although some reports strongly recommended PRP for recalcitrant tennis elbow, a recent systematic review showed strong evidence against PRP use for chronic tennis elbow. ${ }^{28}$ This was a very controversial paper when things were going well for tennis elbow with PRP. Muscle injuries are common sports-related injuries and, perhaps, most controversial with PRP treatment. Some authors questioned the use of PRP in muscle injuries, as animal experiments showed no likely benefit of PRP in muscle injuries. ${ }^{29}$ Further, a year later, another experimental study ${ }^{30}$ concluded that PRP promoted complete tissue restitution between the 7 th and 21st days in experimental muscle injuries. To confuse matters further, a randomized control trial in $2015^{31}$ concluded that there is no benefit of PRP in terms of "return to play," clearly contradicting the results of an earlier randomized trial. ${ }^{14} \mathrm{~A}$ recent comparative study further complemented this conclusion. ${ }^{32}$ Then again, a most recent randomized control trial ${ }^{33}$ concluded that single injection of PRP coupled with rehabilitation program shortened the time to return to sports, suggesting that PRP is recommended for muscle injuries.

\section{ON THE BALANCE...}

Although there is a paucity of data surrounding the use of PRP in sports medicine, some authors believe that PRP can be tried as a therapeutic agent before going under the knife for recalcitrant cases. ${ }^{34}$ However, there is a need for continued investigation into the efficacy of PRP and stem cells in sports medicine. ${ }^{35}$ A major limitation in the interpretation of current evidence is variability in the preparation of these biologic agents. ${ }^{36}$ For the moment, it appears that the use of biological agents in sports medicine is here to stay, as there is no major adverse effect reported so far in the literature. ${ }^{37}$ However, care should be taken while using PRP in acute injuries, such as ankle sprains. ${ }^{38}$

\section{REFERENCES}

1. Banfi G, Corsi MM, Volpi P. Could platelet rich plasma have effects on systemic circulating growth factors and cytokine release in orthopaedic applications? Br J Sports Med 2006 Oct; $40(10): 816$.

2. Sampson S, Gerhardt M, Mandelbaum B. Platelet rich plasma injection grafts for musculoskeletal injuries: a review. Curr Rev Musculoskelet Med 2008 Dec;1(3-4):165-174.

3. Mishra A, Woodall J Jr, Vieira A. Treatment of tendon and muscle using platelet-rich plasma. Clin Sports Med 2009 Jan;28(1):113-125.

4. Hall MP, Band PA, Meislin RJ, Jazrawi LM, Cardone DA. Platelet-rich plasma: current concepts and application in sports medicine. J Am Acad Orthop Surg 2009 Oct;17(10):602-608.

5. Nguyen RT, Borg-Stein J, McInnis K. Applications of plateletrich plasma in musculoskeletal and sports medicine: an evidence-based approach. PM R 2011 Mar;3(3):226-250.

6. Spang JT, Tischer T, Salzmann GM, Winkler T, Burgkart R, Wexel G, Imhoff AB. Platelet concentrate vs. saline in a rat patellar tendon healing model. Knee Surg Sports Traumatol Arthrosc 2011 Mar;19(3):495-502.

7. Kon E, Filardo G, Di Martino A, Marcacci M. Platelet-rich plasma (PRP) to treat sports injuries: evidence to support its use. Knee Surg Sports Traumatol Arthrosc 2011 Apr;19(4): 516-527.

8. Jassim S, Haddad FS. Platelet-rich plasma in sports medicine: hot favourite or non-starter? Br J Hosp Med (Lond) 2012 Feb;73(2):91-94.

9. Anitua E, Sánchez M. We cannot take oranges for apples in the field of platelet-rich plasma products. Scand J Med Sci Sports 2012 Apr;22(2):147-148.

10. Stanco D, Vigano' M, Croiset SJ, De Girolamo L. Applications and limits of platelet-rich plasma in sports related injuries. J Biol Regul Homeost Agents 2012 Apr-Jun;26(2 Suppl 1): 53S-61S.

11. Ahmad Z, Howard D, Brooks RA, Wardale J, Henson FM, Getgood A, Rushton N. The role of platelet-rich plasma in musculoskeletal science. JRSM Short Rep 2012 Jun;3(6):40.

12. Mishra A, Harmon K, Woodall J, Vieira A. Sports medicine applications of platelet-rich plasma. Curr Pharm Biotechnol 2012 Jun;13(7):1185-1195.

13. Hamid MS, Mohamed Ali MR, Yusof A, George J. Platelet-rich plasma (PRP): an adjuvant to hasten hamstring muscle recovery. A randomized controlled trial protocol (ISCRTN66528592). BMC Musculoskelet Disord 2012 Aug;13:138.

14. Hamid MS, Mohamed Ali MR, Yusof A, George J, Lee LP. Platelet-rich plasma injections for the treatment of hamstring injuries: a randomized controlled trial. Am J Sports Med 2014 Oct;42(10):2410-2418.

15. Arnoczky SP, Sheibani-Rad S. he basic science of platelet-rich plasma (PRP): what clinicians need to know. Sports Med Arthrosc 2013 Dec;21(4):180-185.

16. Russell RP, Apostolakos J, Hirose T, Cote MP, Mazzocca AD. Variability of platelet-rich plasma preparations. Sports Med Arthrosc 2013 Dec;21(4):186-190.

17. Eirale C, Mauri E, Hamilton B. Use of platelet rich plasma in an isolated complete medial collateral ligament lesion in a professional football (soccer) player: a case report. Asian J Sports Med 2013 Jun;4(2):158-162.

18. Yuan T, Zhang CQ, Wang JH. Augmenting tendon and ligament repair with platelet-rich plasma (PRP). Muscles Ligaments Tendons J 2013 Aug 11;3(3):139-149. 
19. Barber FA. Platelet-rich plasma for rotator cuff repair. Sports Med Arthrosc 2013 Dec;21(4):199-205.

20. Braun HJ, Wasterlain AS, Dragoo JL. The use of PRP in ligament and meniscal healing. Sports Med Arthrosc 2013 Dec;21(4):206-212.

21. Ahmad CS, Redler LH, Ciccotti MG, Maffulli N, Longo UG, Bradley J. Evaluation and management of hamstring injuries. Am J Sports Med 2013 Dec;41(12):2933-2947.

22. Dold AP, Zywiel MG, Taylor DW, Dwyer T, Theodoropoulos J. Platelet-rich plasma in the management of articular cartilage pathology: a systematic review. Clin J Sport Med 2014 Jan;24(1):31-43.

23. Dragoo JL, Wasterlain AS, Braun HJ, Nead KT. Platelet-rich plasma as a treatment for patellar tendinopathy: a doubleblind, randomized controlled trial. Am J Sports Med 2014 Mar;42(3):610-618.

24. Atesok K, Fu FH, Wolf MR, Ochi M, Jazrawi LM, Doral MN, Lubowitz JH, Rodeo SA. Augmentation of tendon-to-bone healing. J Bone Joint Surg Am 2014 Mar 19;96(6):513-521.

25. Tsikopoulos K, Tsikopoulos A, Natsis K. Autologous whole blood or corticosteroid injections for the treatment of epicondylopathy and plantar fasciopathy? A systematic review and meta-analysis of randomized controlled trials. Phys Ther Sport 2016 Nov;22:114-122.

26. Brkljac M, Kumar S, Kalloo D, Hirehal K. he effect of plateletrich plasma injection on lateral epicondylitis following failed conservative management. J Orthop 2015 Nov;12(Suppl 2): S166-S170.

27. Murray DJ, Javed S, Jain N, Kemp S, Watts AC. Platelet-richplasma injections in treating lateral epicondylosis: a review of the recent evidence. J Hand Microsurg 2015 Dec;7(2):320-325.

28. de Vos RJ, Windt J, Weir A. Strong evidence against plateletrich plasma injections for chronic lateral epicondylar tendinopathy: a systematic review. Br J Sports Med 2014 Jun;48(12): 952-956.
29. Delos D, Leineweber MJ, Chaudhury S, Alzoobaee S, Gao Y, Rodeo SA. The effect of platelet-rich plasma on muscle contusion healing in a rat model. Am J Sports Med 2014 Sep;42(9): 2067-2074.

30. Quarteiro ML, Tognini JR, de Oliveira EL, Silveira I. The effect of platelet-rich plasma on the repair of muscle injuries in rats. Rev Bras Ortop 2015 Aug;50(5):586-595.

31. Hamilton B, Tol JL, Almusa E, Boukarroum S, Eirale C, Farooq A, Whiteley R, Chalabi H. Platelet-rich plasma does not enhance return to play in hamstring injuries: a randomised controlled trial. Br J Sports Med 2015 Jul;49(14):943-950.

32. Guillodo Y, Madouas G, Simon T, Le Dauphin H, Saraux A. Platelet-rich plasma (PRP) treatment of sports-related severe acute hamstring injuries. Muscles Ligaments Tendons J 2016 Feb;5(4):284-288.

33. Rossi LA, Molina Rómoli AR, Bertona Altieri BA, Burgos Flor JA, Scordo WE, Elizondo CM. Does platelet-rich plasma decrease time to return to sports in acute muscle tear? A randomized controlled trial. Knee Surg Sports Traumatol Arthrosc 2017 Oct;25(10):3319-3325.

34. Grambart ST. Sports medicine and platelet-rich plasma: nonsurgical therapy. Clin Podiatr Med Surg 2015 Jan;32(1):99-107.

35. Gobbi A, Fishman M. Platelet-rich plasma and bone marrowderived mesenchymal stem cells in sports medicine. Sports Med Arthrosc 2016 Jun;24(2):69-73.

36. Kopka M, Bradley JP. The use of biologic agents in athletes with knee injuries. J Knee Surg 2016 Jul;29(5):379-386.

37. Mlynarek RA, Kuhn AW, Bedi. Platelet-Rich Plasma (PRP) in orthopedic sports medicine. Am J Orthop (Belle Mead NJ) 2016 Jul-Aug;45(5):290-326

38. Rowden A, Dominici P, D'Orazio J, Manur R, Deitch K, Simpson S, Kowalski MJ, Salzman M, Ngu D. Double-blind, randomized, placebo-controlled study evaluating the use of platelet-rich plasma therapy (PRP) for acute ankle sprains in the emergency department. J Emerg Med 2015 Oct;49(4):546-551. 